\title{
A Mathematical Model of Ranking Coaches
}

\author{
Y. Gao, R. Wang, X. Li, Z.L. Jiang \\ Department of Mathematics, Sun Yat-Sen University, Guangzhou, China, 51027
}

\begin{abstract}
This paper gives a mathematical model to evaluate a college coach by use of a fuzzy hierarchical evaluation approach. In this approach, an analytic hierarchy process (AHP) is first used to give a proper weight for each influential factor. Then these weights are applied in computing the grade of a coach by use of a fuzzy comprehensive evaluation. Meanwhile, an impact factor is introduced to reflect some social influences like commercial value, popularity and devotion, which are normally hard to be quantified. The accuracy of the impact factor is guaranteed by cluster analysis of coaches' active years. Finally, an experimental sample of this model is shown for comparison with other ranking results.
\end{abstract}

Keywords-AHP; fuzzy comprehensive evaluation; ranking model; college coaches

\section{INTRODUCTION}

Obviously, sports play a very significant role in America college system. Sports games are not only regarded as entertainment for students and audiences, but also exert a considerable influence on students' future and college's reputation. Among many factors, college coach is a quite influential one. Though there are various rankings of college coaches available in magazines or on sports websites, they have usually lack of scientific criteria to carry out and explain their rankings. Some of them have no precise explanation of their ranking standard, but merely list out coaches' results and prominent performances. Others merely rank recently active coaches, and have not compared coaches from different times. Generally speaking, these ranking results may be given by subjective judgments that over-rely on some factors, and their explanations are equivocal. In this paper, a mathematical method is used to quantify the rank of college coaches over a certain period.

To quantify this rank, it is necessary to find factors reflecting a coach's ability and influence to a large degree. The choice of factors relies on the social general standard and expectation for a qualified coach. The factors to be considered are as follows: Years (the years of his/her coaching career in college), Games (the total numbers of games during his/her coaching career in college), Wins (the total number of games a coach wins in his/her coaching career in college), Win percentage (Wins/Games), Annual average wins (Wins/Years). Though these factors reflect a coach's ability indeed, we still lack some important factors to represent social impact of a coach, so we base on a volume of search on certain sports website to represent such impact.

Then, these weighted factors are taken as parameters in a fuzzy comprehensive evaluation to give each coach a grade by which we are able to rank them. This evaluation is derived from the fuzzy set theory introduced by Zadeh and Klaua (e.g., see [2],[5],[9],[10]), and used to solve decisionmaking problems that are hard to quantify without a generally subjective standard, because it builds a structural evaluation system and results in an exact grade. It has appeared in many different fields (e.g., see [6]). But a very crucial aspect in our evaluation is the choice of the weights of parameters. Thus we need an analytic hierarchy process (AHP) to carry out a proper weight for each parameter.

AHP, which was developed by Saaty [8] in the 1970's, is based on a mathematical and psychological theory and offers a scientifically proper technique to make some complex decisions. Since then, AHP has been widespread used in different fields like ecology, human resource management, quality analysis and business. For example, AHP has been used by McCaffrey [7] to analyze the total quality of software, and by Grandzol [3] to choose university faculty. In this paper, AHP is applied in giving each factor a scientific and quantifiable weight since such process can eliminate over-relying and subjective judgments to a large degree.

This paper is roughly managed as follows. At the beginning of Section 2, our core algorithm is introduced and it is derived from the fuzzy comprehensive evaluation. Because the weights of different factors are needed in this evaluation, we take advantage of AHP to calculate a more scientific weight of each factor in Section 2.1. On the basis of two main algorithms, we introduce a factor named as "Impact Factor" to influence and improve the result in Section 2.2. After devising a proper solution to rank coaches, we take American football as a sample to realize our ranking algorithm in Section 3. We select several important factors of football coaches as parameters in this algorithm and build a mathematical model of these coaches by our algorithm. Then, by Matlab, we process this algorithm, and obtain our results for our comparison with other ranking results in sports media.

\section{MATHEMATICAL MODEL OF RANKING COACHES}

Our core algorithm is derived from the fuzzy comprehensive evaluation, as follows.

Suppose that $U=\left\{u_{1}, u_{2}, \cdots, u_{m}\right\}$ is a vector where $u_{i}$ means the $\mathrm{i}^{\text {th }}$ factor of a coach, $\mathrm{i}$ belongs to $\{1,2, \cdots, \mathrm{m}\}$ and $\mathrm{m}$ is the number of factors.

First, the values of 5 factors of a coach are standardized by use of the following formula:

$$
\mathrm{u}_{\text {inew }}=\left(\mathrm{u}_{\mathrm{i}}-\mathrm{u}_{\text {imin }}\right) /\left(\mathrm{u}_{\mathrm{imax}}-\mathrm{u}_{\mathrm{imin}}\right) \text {, }
$$

where $u_{\text {inew }}$ is the standardization value of the $i^{\text {th }}$ factor of a coach, $u_{i m i n}$ and $u_{i m a x}$ are the minimum and maximum of the five factors, respectively. Then the grades of factors are determined by using the standardization value. For standardization values of factors, we choose 10 grades given as in Tab. 1 where the numbers in the first row represent the grades of factors corresponding to their column ranges of standardization values in the second row. 
TABLE 1. GRADES OF FACTORS AND RANGES OF STANDARDIZATION VALUES.

\begin{tabular}{|c|c|c|c|c|c|c|c|c|c|}
\hline 1 & 2 & 3 & 4 & 5 & 6 & 7 & 8 & 9 & 10 \\
\hline $0.0 \sim 0.1$ & $0.1 \sim 0.2$ & $0.2 \sim 0.3$ & $0.3 \sim 0.4$ & $0.4 \sim 0.5$ & $0.5 \sim 0.6$ & $0.6 \sim 0.7$ & $0.7 \sim 0.8$ & $0.8 \sim 0.9$ & $0.9 \sim 1.0$ \\
\hline
\end{tabular}

Now, assuming that $\mathrm{n}$ is the total number of grades, we introduce a $\mathrm{m} \times \mathrm{n}$ matrix $\mathrm{R}=\left\{\mathrm{r}_{\mathrm{ij}}\right\}$, a $1 \times \mathrm{m}$ matrix $\mathrm{A}=\left\{\mathrm{a}_{1}, \mathrm{a}_{2}, \cdots, \mathrm{a}_{\mathrm{m}}\right\}$ and a $1 \times \mathrm{n}$ matrix $\mathrm{V}=\left\{\mathrm{v}_{1}, \mathrm{v}_{2}, \cdots, \mathrm{v}_{\mathrm{n}}\right\}$, where $\mathrm{r}_{\mathrm{ij}}$, $\mathrm{a}_{\mathrm{i}}$ and $\mathrm{v}_{\mathrm{j}}$ are explained as follows.

$\mathrm{r}_{\mathrm{ij}}$ means the degree at which the $\mathrm{i}^{\text {th }}$ factor belongs to the $\mathrm{j}^{\text {th }}$ grade and it is defined as $\mathrm{r}_{\mathrm{ij}}=\mathrm{u}_{\text {inew }}$ if the $\mathrm{i}^{\text {th }}$ factor belongs to the $\mathrm{j}^{\text {th }}$ grade, otherwise $\mathrm{r}_{\mathrm{ij}}=0$. $\mathrm{a}_{\mathrm{i}}$ is the nonnegative weight of the $\mathrm{i}^{\text {th }}$ factor, so that $\mathrm{a}_{1}+\mathrm{a}_{2}+\cdots+\mathrm{a}_{\mathrm{m}}=1$, and it can be below calculated by AHP. $v_{j}$ is defined as

$$
v_{j}=a_{1} r_{1 j}+a_{2} r_{2 j}+\cdots+a_{m} r_{m j} \text {, }
$$

or say, $\mathrm{V}$ is a product of $\mathrm{A}$ and $\mathrm{R}$, that is, $\mathrm{V}=\mathrm{AR}$.

$\mathrm{v}_{\mathrm{j}}$ means the degree at which a coach belongs to the $\mathrm{j}^{\text {th }}$ grade, or say, it represents an evaluation result at the $\mathrm{j}^{\text {th }}$ grade for a coach. $|\mathrm{V}|$ is defined as $|\mathrm{V}|=\mathrm{v}_{1}+\mathrm{v}_{2}+\cdots+\mathrm{v}_{\mathrm{n}}$, that is, it is indeed the total value of all the evaluation results at all the grades for a coach. $|\mathrm{V}|$ is our final result and it is regarded as a score for a coach.

\section{A. Relation with AHP for ranking}

By using AHP, once selected, these factors of a coach are arranged in a hierarchic structure descended from an overall goal to criteria, sub-criteria, and alternatives in successive levels.
A hierarchy does not need to be complete, that is, an element in a given level does not have to function as an attribute (or criterion) for all the elements in the level below. Elements that have a global character can be represented at the higher levels of the hierarchy, and others that specifically characterize the problem at hand can be developed in the greater depth. The task of setting priorities requires that the criteria, the properties of features of the alternatives being compared, and the alternative themselves are gradually layered in the hierarchy so that it is meaningful to compare them among themselves in relation to the elements of the next higher level.

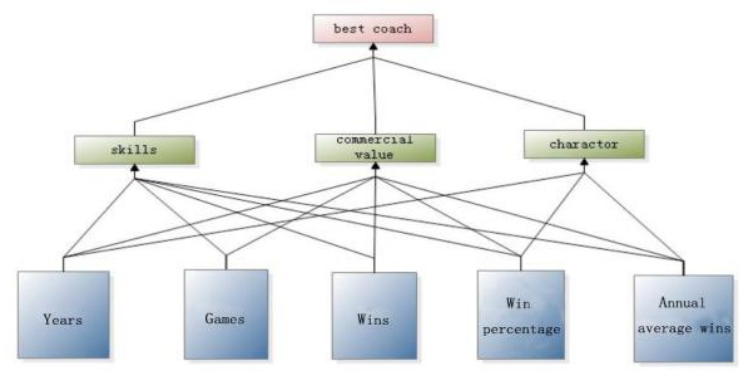

FIGURE 1. A HIERARCHY CHART FOR A COACH.

TABLE 2. THE ABSOLUTE INTENSITY OF IMPACT.

\begin{tabular}{|c|c|c|}
\hline $\begin{array}{l}\text { Absolute intensity } \\
\text { of impact }\end{array}$ & Definition & Explanation \\
\hline 1 & Equal importance & $\begin{array}{l}\text { Two factors contribute equally to } \\
\text { the same coach }\end{array}$ \\
\hline 5 & Essential or strong impact & The impact of Factor A is strong with respect to Factor B \\
\hline 7 & Very strong impact & The impact of Factor A is very strong with respect to Factor B \\
\hline 9 & Extreme impact & $\begin{array}{l}\text { The impact of Factor } \mathrm{A} \text { is extremely strong with respect to } \\
\text { Factor B }\end{array}$ \\
\hline $2,4,6,8$ & $\begin{array}{l}\text { Intermediate values between } \\
\text { the two adjacent judgments }\end{array}$ & When compromise is needed \\
\hline Reciprocals & \multicolumn{2}{|c|}{$\begin{array}{l}\text { If activity } \mathrm{i} \text { has one of the above numbers assigned to it when compared with activity } \mathrm{j} \text {, then } \mathrm{j} \text { has the reciprocal value when } \\
\text { compared with } \mathrm{i}\end{array}$} \\
\hline Rationals & Ratios arising from the scale & $\begin{array}{l}\text { If consistency is forced by obtaining } \\
\mathrm{n} \text { numerical values to span the matrix }\end{array}$ \\
\hline
\end{tabular}

Such a hierarchy is layered as in Fig. 1. Its bottom layer contains Years, Games, Wins, Win percentage and Annual average wins, which are sub-criteria. Its middle layer consists of skills, commercial value and character, which are on the higher level of hierarchy, and have more dominant influence on the final decision. As we can see, the hierarchy is not complete, "Games" and "Wins" do not influence "character", but it is allowed.

Then, we use standard scales to compare the relative importance of elements in every layer. These standard scales represent the different intensities of importance on an absolute scale and they are listed in Tab. 2. Each two factors in the same layer need to be compared by use of these scales.

Practically, with the help of a kind of AHP software, we can build a hierarchy and compare each two factors, thus getting the weights that minimize the subjective judgment.

\section{B. How "Impact Factor" influences and improves the result}

Evaluation of coaches is not an easy thing just like identifying which orange is sourest. Ranking coaches, we consider not only such quantifiable factors as "Wins" and "Years", but also many other influential factors like commercial value, popularity, devotion and so on. But sometimes such kinds of social factors are hard to quantify, so we come up with an idea to use a new factor called "Impact Factor". It is quantified by a "Search Volume" which can be defined as the quantity of result that comes out from a certain search engine. The Search quantity may be 
used well in this model as it can reflect a coach's popularity, social influence and devotion to the game to some extent.

To insure the precision of the impact factor, we make the following assumptions:

1) Some abnormal search quantities can be identified and corrected;

2) Search has commercial value, and Search has relationship with the coach's character and the coach's skills, and scandal does not interfere with the ranking result severely;

3) The information in a search engine we use is authentic and reliable to reflect the import factor.

Numerical value of "Import Factor" could be largely influenced by the active period of coaches. For instance, the quantity of an excellent coach 50 years ago is much less a popular coach now, but it does not mean that the former one is not as influential as the latter. Thus, we use cluster analysis [4] to divide coaches into different groups according to their active period and numerical features of other factors, and then give them a standardized value of "Impact Factor". Cluster analysis is a kind of method to group a set of objects in such a way that objects in the same group (cluster) are more similar (in some sense or another) to each other than to those in other groups (clusters).

\section{EXPERIMENTAL RESULTS}

National Collegiate Athletic Association (NCAA) is the biggest athletic association in the United States and Canada, and has held most collegiate sports games. Therefore we can search the sufficient result collection of games of coaches in the NCAA database, and select important factors in the database based on our criteria. Since football is the most popular and influential sport in America, football coaches in the latest century are chosen as samples to rank in our model.

Considering professional and searching ability, we eventually choose the ESPN website search engine to get some data for "Impact Factor". We first take the previous 100 coaches existing in the ranking lists online, and then get their search volume from the ESPN website which is nearly the biggest sports fans' website loved by Americans. Using the list of intensities in Tab. 2, the impact intensities of these coaches are judged by requirement of coaches from the NCAA official website. According to these intensities, we first assume that the ratios of every pair of the five factor values are displayed in Fig. 2. These ratios turn out to a priority matrix in our program designed according to AHP.

\begin{tabular}{|c|c|c|c|c|c|}
\hline & Ganes & Wins & Win percentage & Years & Annual aver age wins \\
\hline Games & & $1 / 6$ & $1 / 7$ & 1 & $1 / 6$ \\
\hline Wins & & & $1 / 3$ & 3 & 1 \\
\hline Win percentage & & & & 4 & 2 \\
\hline Years & & & & & $1 / 4$ \\
\hline Annual average wins & & & & & \\
\hline
\end{tabular}

FIGURE 2. A PRIORITY MATRIX IN OUR PROGRAM.

Then we make three experiments in three cases, respectively. Case 1 is without considering the impact factor, Cases 2 and 3 have the impact factor. In Case 2, we first sort 100 coaches according to the middle years of their active years and then divide these coaches into ten groups according to equal division of 100 years. In Case 3, 100 coaches are classified into four groups by use of cluster analysis, based on the starting years and ending years.

In Case 1, the weights of all the factors we consider are automatically output by running the program and they are shown as in Fig.3.

In Case 2, considering that the social influence of all the coaches in the past 100 years is also a criterion to evaluate their power, we introduce a new parameter called "impact factor", as we say above. This element is quantified by the data of Search. First, we sort the previous 100 coaches according to their middle year of active years, and divide them into 10 groups according to equal division of the past 100 years. One group is regarded as one Time. There is perhaps no coach in some groups. Then, we rank the data of Search for coaches in each Time and find an order of these coaches according to these data, thus assuming that the score of the most-searching coach is 1 , and that the scores of coaches are $0.9,0.8$, and so on, according to the order of coaches at this Time. Coaches in the same Time can be evaluated by their Search result, and coaches in different Times can use scores to compete fairly. After doing this, we give a new factor, denoted by ROI, which is transformed from Search. Using ROI as the sixth factor, we can build a $(n+1) \times m$ matrix $R$, thus obtaining a new weight vector $A$ by use of AHP, which is our result shown in Fig. 4.

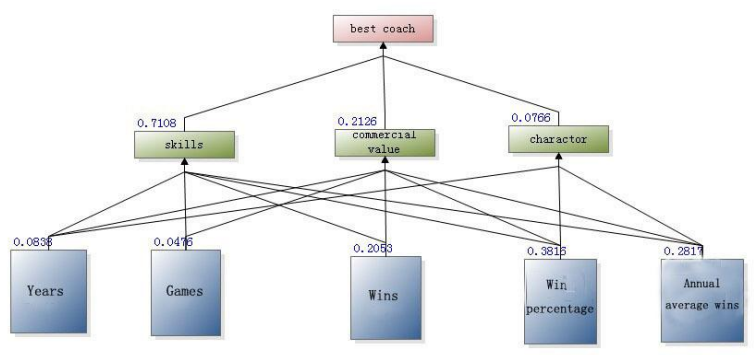

FIGURE 3. THE FACTOR WEIGHTS OBTAINED BY AHP.

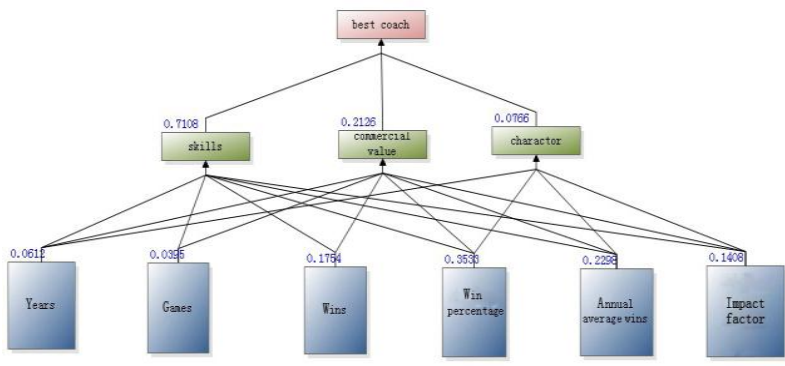

FIGURE 4. THE FACTOR WEIGHTS WHEN CONSIDERING AN IMPACT FACTOR

In Case 3, since the relevance of coaches may be not reflected by simply sorting coaches according to the middle year of their active years, we give another classification of coaches to get factor weights. Based on the starting years and ending years, we classify the previous 100 coaches into four groups by use of cluster analysis. In Fig. 5, five red vertical lines divide 100 coaches into four groups. Then, using $\mathrm{R}$, we can obtain a new factor ROI 2 which is shown in. Using ROI 2 as the sixth factor instead of ROI, we can build a $(n+1) \times m$ matrix $R$. Thus we assign the weights into A in the fuzzy comprehensive evaluation. 


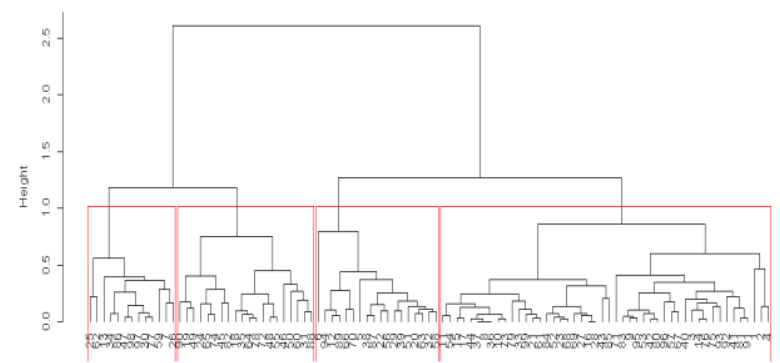

FIGURE 5. THE CLUSTER ANALYSIS RESULT.

Once the weight matrix $\mathrm{A}$ is given, by use of $\mathrm{R}$, we can run our algorithm to give our results. Tab. 3 shows our final results of $|\mathrm{V}|$ for coaches considered in the three cases. These results at Columns score, score 2 and score 3 in this table are obtained in Cases 1, 2 and 3, respectively, corresponding to their ordinal numbers at Columns Rank1, Rank2 and Rank3. These ordinal numbers almost match those given on websites or in magazines.

\section{TABLE 3. RANKS OF COACHES IN THE THREE} CASES.

\begin{tabular}{|l|r|r|r|r|r|r|}
\hline \multicolumn{1}{|c|}{ coach } & score & Rank1 & score2 & Rank2 & score3 & Rank3 \\
\hline Joe Paterno & 74.24445 & 2 & 75.95534 & 1 & 73.47022 & 1 \\
\hline Bear Bryant & 71.34391 & 5 & 73.14735 & 2 & 73.14735 & 2 \\
\hline Urban Meyer & 63.65552 & 8 & 68.44734 & 6 & 69.43998 & 3 \\
\hline John Gagliardi & 79.8 & 168.14412 & 768.14412 & 4 \\
Bob Stoops & 63.24769 & 10 & 65.04059 & 11 & 66.25851 & 5 \\
\hline Bobby Bowden & 71.76638 & 4 & 73.0169 & 3 & 66.0825 & 6 \\
\hline Eddie Robinson & 65 & 6 & 65.34122 & 10 & 65.34122 & 7 \\
\hline Pete Carrol1 & 59.57371 & 15 & 63.51739 & 12 & 65.00987 & 8 \\
\hline Tom Osborne & 72.65363 & 3 & 71.04418 & 4 & 64.52514 & 9 \\
\hline
\end{tabular}

\section{CONCLUSION AND DISCUSSION}

A mathematical model is designed to rank coaches from different fields and times. It is not based on subjective judgment, but uses AHP to give influential factors proper weights. Not only are such traditional ranking standards as weighted mean taken to rank coaches. AHP is combined with the fuzzy comprehensive evaluation to turn such [11] cientific, 1996. unquantifiable problems into a clearly structural evaluation system. Also, our model is not limited in years and easily quantifiable data. The impact factor is introduced to reflect social and commercial influence of coaches, and cluster analysis removes the inaccuracy produced by different active years of coaches. It is finally found that our ranking results almost recover those given on websites or in magazines. This means that our mathematical model is valid.

\section{ACKNOWLEDGEMENT}

This work is supported by the National Base Training Foundation for Construction Projects, and by the National Natural Science Foundation of China (NSFC 11171356).

\section{REFERENCE}

[1] Everitt, B.S., Landau, S. and Leese, M., Cluster Analysis, Fourth Ed., London: Arnold Publishers, 2001

[2] Gottwald, S., An early approach toward graded identity and graded membership in set theory, Fuzzy Sets and Systems, 161(18), 2010, p.2369-2379.

[3] Grandzol, J.R., Improving the Faculty Selection Process in Higher Education: a case for the analytic hierarchy process. IR Applications, 6, 2005, p.1-13

[4] Jolliffe, I., Principal component analysis, John Wiley \& Sons, Ltd, 2005.

[5] Klaua, D., Über einen Ansatz zur mehrwertigen Mengenlehre, Monatsb. Deutsch. Akad. Wiss. Berlin 7, 1965, p.859-876.

[6] Ma, Y., Wang Z. G.,Yang Z., Fuzzy comprehensive method for gas turbine evaluation, Proceedings of CSEE, 10, 9, 2003, p.218-220.

[7] McCaffrey, J., Test Run-The analytic hierarchy process, MSDN Magazine, 6, 2005, p.139-146.

[8] Saaty, T.L., How to make a decision: the analytic hierarchy process, European journal of operational research, 48, 1, 1990, p.9-26.

[9] Zadeh, L.A., Fuzzy sets, Information and Control, 8(3), 1965, p.338353.

[10] Zadeh, L.A., Fuzzy Sets, Fuzzy Logic, and Fuzzy Systems, Edited by Georg J. Klir and Bo Yuan, World S 